\title{
Total knee replacement for patients with severe hemophilic arthropathy in Taiwan: A nationwide population-based retrospective study
}

Cheng-Fong Chen ( $\sim$ doc2751g@gmail.com )

National Yang-Ming University School of Medicine https://orcid.org/0000-0002-2485-6159

Yuan-Bin Yu

Taipei Veterans General Hospital

Jan-Wei Chiu

Taipei Veterans General Hospital

Jyh-Pyng Gau

Taipei Veterans General Hospital

Hui-Chi Hsu

Taipei Veterans General Hospital

\section{Research Article}

Keywords: total knee replacement, hemophilia, epidemiology, population-based study, Taiwan

Posted Date: March 23rd, 2021

DOI: https://doi.org/10.21203/rs.3.rs-339590/v1

License: (9) This work is licensed under a Creative Commons Attribution 4.0 International License.

Read Full License

Version of Record: A version of this preprint was published at Journal of the Chinese Medical Association on October 25th, 2021. See the published version at https://doi.org/10.1097/JCMA.0000000000000646. 


\section{Abstract}

\section{Background}

Total knee replacement (TKR) surgery is a treatment option for advanced hemophilic arthropathy. Due to its rarity and complexity, previous reports could only demonstrate the results of single-site studies including few cases. This population-based study aimed to investigate the major epidemiological characteristics, mean consumption of coagulation factors, length of hospital stays, complications, and failure rate of primary TKR for severe hemophilia patients in Taiwan.

\section{Methods}

A cohort of 996 hemophilia patients registered between 1995 and 2011 were included, and 103 primary TKRs were performed on 75 patients. Unilateral TKR was performed on 47 patients and bilateral TKRs on the remaining 28 patients, including 12 simultaneous and 16 staged surgeries. The mean age at surgery was 32.3 years (range: $17.3-55.7$ ), and the mean follow-up duration was 77.9 months (range: $2.3-$ 176.8).

\section{Results}

Failure was noted in 8 patients (8.5\%) at mean 32.8 months (range: $2.3-95)$ after surgery. Four patients revealed aseptic loosening, whereas infection in 4 . The 10 -year prosthesis survivorship was $88.6 \%$. For patients receiving unilateral TKR, the mean length of hospital stay was 15 days (range: 7-32). The mean cost of factor supplement was USD 43,543 with a mean 4-unit packed RBC transfusion (range: 0-38). The total admission cost was USD 48,326 (range: USD 4,165-262,619).

\section{Conclusions}

The prevalence of TKA for hemophilia patients was $7.5 \%$ in Taiwan. The mean hospital stays was 14 days and the 10 -year prosthesis survivorship was $88.6 \%$. The mean daily factors usage was decreased from 235.7 unites preoperatively to 202.1 units postoperatively. In comparison with the staged-bilateral TKRs, the simultaneous procedures significantly reduced the mean total cost from USD 101,923 to USD 61,587 ( $P=0.023)$. Therefore, in terms of cost-effectiveness, bilateral simultaneous TKR is more preferable than staged procedures.

\section{Background}

The knee is the most commonly involved joint tissue in hemophilia patients [1-3]. Recurrent hemoarthrosis may result in chronic synovitis and advanced hemophilic arthropathy at the end-stage of the disease. The symptoms include severe pain, limited range of motion (ROM), and impaired knee function. Total knee replacement (TKR) is an effective surgery in association with sustainable pain relief and function recovery for the general population. However, for patients with hemophilic arthropathy, severe deformity, soft tissue contracture, and disused juxta-articular osteoporosis compromise the 
advantages of TKR. Hence, an improved surgical technique is required for this purpose. Few of the earliest reports of TKR in patients with hemophilia were published in the mid-1970s [4,5]. With the improvement in the surgical techniques and medical management, the outcomes of TKR performed on hemophiliac patients are presently satisfactory [6-9]. However, high incidences of complications including bleeding, deep infection, prosthetic failure, and limited ROM have been reported in several studies $[7,11]$.

Bilateral involvement of hemarthrosis over knee joints are frequent in patients with severe hemophilia and TKR is the standard management. In this setting, it is not clear whether simultaneously bilateral TKR or staged TKR should be performed in those hemophiliac patients. Therefore, we conduct the nationwide study to investigate the safety and cost-effectiveness of TKR in Taiwanese hemophiliac patient population.

\section{Methods}

\section{Study population and cohort}

Since 1995, the National Health Insurance (NHI) program initiated by the Taiwanese government has been providing mandatory health insurance policies. By the end of year 2011 , approximately $99.59 \%$ of Taiwanese citizens were registered under effective medical coverage. The present study is a retrospective population-based study that explored the authentic data extracted from the National Health Insurance Research Database (NHIRD) of Taiwan. The NHIRD nearly contains all inpatient and outpatient medical benefit claims for about 23 million Taiwanese residents. The claim files comprise of outpatient and inpatient medical records, including diagnosis, treatment, and all management incurring expenses. This study was exempted from full review by the Institutional Review Board.

\section{Data mining}

We identified all patients diagnosed with hemophilia (ICD-9-CM codes 286) for the first time between January 1, 1995 and December 31, 2011. Simultaneous TKR was defined as bilateral TKR performed at the same surgical day, while staged-bilateral TKR was defined as two TKR procedures performed at different hospitalization. Implant failure was defined as revision or removal of prosthesis. The diagnosis was confirmed by the Registry for Catastrophic Illness Patient Database (RCIPD), a subset of the NHIRD. Laboratory confirmation of the clotting factor was required for patients to be registered in the RCIPD.

By using the data extracted from NHIRD, we obtained a cohort of 996 hemophilia patients between 1995 and 2011. The study inclusion criteria were registration in the claim-specific reimbursement codes of primary TKR (64164B), revision TKR (64198B), and prosthesis removal (64202B). The end-point of implant survival was determined by revision or removal of prosthesis due to infection or aseptic loosening. Prosthesis survivorship was calculated, with failure defined as revision or removal of the prosthesis. Surgical failures characterized as revision or removal of the prosthesis was used to calculate the prosthesis survivorship. The follow-up time began at the first admission date and ended at the 
implant failure date, patient's death, or the end of 2011, whichever came first. Our follow-up study continued until the end of 2011. For each enrolled subject, the data, including demographic variables, year of receiving surgery, surgical type, costs of the prescribed coagulation factors, coagulation factor usage of 12 months before surgery and at 1-6 months and 7-18 months after surgery, transfusion amounts, length of hospital stay, and total costs of hospitalization were extracted and categorized.

\section{Statistical Analysis}

The data from the NHIRD was managed using the Microsoft SQL Server 2008 R2. SPSS statistical software version 20.0 for Windows (SPSS, Inc., Chicago, IL, USA) was used to perform all the analyses. The prosthesis-failure-free survival was plotted by the Kaplan-Meire method. Comparisons among unilateral TKR, staged-bilateral TKR, and simultaneous-bilateral TKR were conducted by ANOVA test, chisquare test, or Student's $t$-test. The mean daily factor usage before and after TKR was examined using the paired Student's $t$-test. Two-tailed $p<0.05$ was considered to be significant.

\section{Results}

During the period between 1995 and 2011, 996 hemophilia patients were registered in the NHIRD of Taiwan. Among these patients, 103 primary TKR surgeries were performed on 75 patients (7.5\%) with severe hemophilic arthropathy (Fig. 1). Sixty-three patients were diagnosed with hemophilia A and the remaining 12 with hemophilia B. Hemophilia patients with factor VIII inhibitor or HIV were not enrolled in the study. Unilateral TKR surgery was performed on 47 patients, whereas 28 patients received bilateral TKR, including 12 simultaneous TKR and 16 staged TKR in two consecutive admissions (Table 1).

Table 1

The prevalence of total knee replacement procedures in hemophiliacs in Taiwan (19972011)

\begin{tabular}{|llll|}
\hline & $\begin{array}{l}\text { Total } \\
(\mathbf{n = 9 9 6 )}\end{array}$ & $\begin{array}{l}\text { Hemophilia A } \\
(\mathbf{n = 8 3 0 )}\end{array}$ & $\begin{array}{l}\text { Hemophilia B } \\
(\mathbf{n}=\mathbf{1 6 6})\end{array}$ \\
\hline Total No. of patient who received TKR & $75(7.5 \%)$ & 63 & 12 \\
\hline Total No. of TKR & 103 & 86 & 17 \\
\hline Unilateral TKR & 47 & 40 & 7 \\
\hline Bilateral TKR & 28 & 23 & 5 \\
\hline Simultaneous & 12 & 10 & 2 \\
\hline Staged & 16 & 13 & 3 \\
\hline Failure & $8(7.8 \%)$ & $8(9.3 \%)$ & $0(0 \%)$ \\
\hline Aseptic loosening & $4(3.8 \%)$ & $4(4.7 \%)$ & $0(0 \%)$ \\
\hline Deep Infection & $4(3.8 \%)$ & $4(4.7 \%)$ & $0(0 \%)$ \\
\hline
\end{tabular}


The mean age of the patients was 32.3 years (range, $17.3-55.7$ years) at the time of index surgery, and the mean follow-up duration was 77.9 months (range, 2.3-176.8 months). The mean hospital stay was 14 days (range, 6-36 days). Among the 103 TKR implants, 8 (8.5\%) were revised, removed, or converted to a knee arthrodesis at a mean duration of 32.8 months (range, 2.3-95 months) after surgeries. Four cases were derived from aseptic loosening, and 4 were caused by infections. The 10 -year prosthesis survivorship was $88.6 \%$ (Fig. 2).

We further analyzed the amount of coagulation factors used before and after TKR. Table 3 demonstrates that the mean daily consumption of coagulation factor was 235.7 units (range: $0-2884.3$ ) before the surgery in all hemophilic patients, which increased significantly during the first 6 months after TKR (364.9 units, $\mathrm{P}=0.002)$ but later decreased to 202.1 units after 18 months of surgery $(P=0.633)$. No significant difference in the daily factor consumption was noted in hemophilic patients before and 18 months after the TKR. Regarding the difference between the two types of hemophilia, less amount of coagulation factor was postoperatively prescribed for patients with hemophilia B than that in hemophilia A in 18 months after TKR (205.9 U/day vs.178.4 U/day, respectively) (Table 3).

To evaluate the cost-effectiveness of TKR surgeries performed on hemophilic patients, the direct costs of factor supplement, total admission costs, length of hospital stay, and PRBC transfusion for the surgeries of simultaneous-bilateral TKR were compared with that of unilateral TKR and staged-bilateral TKR surgeries (Table 2; Fig. 3). For patients receiving unilateral TKR surgery, the mean length of hospital stay was 15 days (range, 7-32 days) and the mean cost of factor supplement was USD 43,543. An average of four packed RBC units was transfused (range: 0-38 U), and the mean total admission cost was USD 48,326 (range, USD 4,165-USD 262,619). 
Table 2

Comparisons between unilateral TKR, staged bilateral TKR, and simultaneous bilateral TKR

\begin{tabular}{|c|c|c|c|c|c|c|c|}
\hline & $\begin{array}{l}\text { Unilateral } \\
(n=46 *)\end{array}$ & $\begin{array}{l}\text { Staged } \\
(n=16)\end{array}$ & & & $\begin{array}{l}\text { Simultaneous } \\
\left(n=11^{*}\right)\end{array}$ & $P^{1}$ & $P^{2}$ \\
\hline & & $1 \mathrm{st}$ & 2nd & Total & & & \\
\hline Hemophilia A & $39(84.8)$ & & & $13(81.3)$ & $9(81.8)$ & 0.919 & \\
\hline \multicolumn{8}{|l|}{ Age } \\
\hline Median & $\begin{array}{l}32.1 \\
(17.3- \\
55.7)\end{array}$ & $\begin{array}{l}32.9 \\
(23.7- \\
49.8)\end{array}$ & $\begin{array}{l}37.3 \\
(26.5- \\
54.9)\end{array}$ & & $\begin{array}{l}30.0(24.5- \\
49.7)\end{array}$ & & \\
\hline$<=30$ & $18(39.1)$ & $8(50)$ & $6(37.5)$ & & $6(54.5)$ & 0.711 & \\
\hline$>30$ & $28(60.9)$ & $8(50)$ & $10(62.5)$ & & $5(45.5)$ & & \\
\hline Era & & & & & & 0.202 & \\
\hline Before 2004 & $23(50.0)$ & $11(68.8)$ & $6(37.5)$ & & $6(54.5)$ & & \\
\hline After 2004 & $23(50.0)$ & $5(31.2)$ & $10(62.5)$ & & $5(45.5)$ & & \\
\hline $\begin{array}{l}\text { Hospitalization } \\
\text { days }\end{array}$ & $\begin{array}{l}15(7- \\
32)\end{array}$ & $\begin{array}{l}12.5(6- \\
30)\end{array}$ & $\begin{array}{l}11(7- \\
36)\end{array}$ & $\begin{array}{l}23.5 \\
(14-53)\end{array}$ & $15(9-20)$ & 0.703 & 0.001 \\
\hline \multirow{2}{*}{$\begin{array}{l}\text { Factor usage } \\
\text { (USD) }\end{array}$} & 43543 & 41805 & 47912 & 93878 & 54737 & 0.091 & 0.044 \\
\hline & $\begin{array}{l}(93- \\
258785)\end{array}$ & $\begin{array}{l}(7245- \\
86816)\end{array}$ & $\begin{array}{l}(17131- \\
255125)\end{array}$ & $\begin{array}{l}(34250- \\
328633)\end{array}$ & $\begin{array}{l}(18008- \\
126482)\end{array}$ & & \\
\hline \multirow{2}{*}{$\begin{array}{l}\text { Transfusion } \\
\text { amount }\end{array}$} & 4 & 2 & 2 & 3 & 8 & 0.287 & 0.183 \\
\hline & $(0-38)$ & $(0-12)$ & $(0-14)$ & $(0-26)$ & $(2-16)$ & & \\
\hline \multirow{2}{*}{$\begin{array}{l}\text { Admission } \\
\text { cost (USD) }\end{array}$} & 48326 & 46427 & 52574 & 101932 & 61587 & 0.096 & 0.023 \\
\hline & $\begin{array}{l}(4165- \\
262619)\end{array}$ & $\begin{array}{l}(11515- \\
96956)\end{array}$ & $\begin{array}{l}(21636- \\
262011)\end{array}$ & $\begin{array}{l}(43067- \\
345933)\end{array}$ & $\begin{array}{l}(26159- \\
134497)\end{array}$ & & \\
\hline Failure & $7(15.2)$ & & & $1(6.3)$ & $0(0)$ & 0.188 & 1.000 \\
\hline \multicolumn{8}{|c|}{$P^{1}$ : Simultaneous vs. Unilateral vs. Staged $1 \mathrm{st}$ vs. Staged 2 nd } \\
\hline
\end{tabular}


Table 3

Comparison of mean daily factor usage before and after surgery

\begin{tabular}{|c|c|c|c|c|}
\hline & \multirow{2}{*}{$\begin{array}{l}\text { Preoperative* } \\
\text { Mean }\end{array}$} & \multicolumn{2}{|c|}{ Postoperative } & \multirow[t]{2}{*}{$P$ value } \\
\hline & & $\begin{array}{l}\text { Interval } \\
\text { (month) }\end{array}$ & Mean & \\
\hline \multirow[t]{3}{*}{ All $(n=75)$} & $235.7(0-2884.3)$ & 1 & $280.8(0-3973.6)$ & 0.067 \\
\hline & & 6 & $364.9(0-4584.9)$ & 0.002 \\
\hline & & 18 & $202.1(0-1671.9)$ & 0.633 \\
\hline \multirow{3}{*}{$\begin{array}{l}\text { Haemophilia A }(n= \\
63)\end{array}$} & $235.6(0-2884.3)$ & 1 & $277.9(0-3973.6)$ & 0.162 \\
\hline & & 6 & $363.2(0-4584.9)$ & 0.007 \\
\hline & & 18 & $205.9(0-1671.9))$ & 0.806 \\
\hline \multirow[t]{3}{*}{$\begin{array}{l}\text { Haemophilia B ( } n= \\
\text { 12) }\end{array}$} & $\begin{array}{l}413.5(17.3- \\
615.4)\end{array}$ & 1 & $323.5(0-2313.0)$ & 0.155 \\
\hline & & 6 & $410.9(22.5-1278.3)$ & 0.064 \\
\hline & & 18 & $178.4(0-710.1)$ & 0.323 \\
\hline
\end{tabular}

Regarding the bilateral TKRs, the mean length of hospital stay was 15 days (range, 9-20 days) in patients receiving simultaneous-bilateral TKR, and the cumulative hospital stay was 23.5 days (range, 14-53 days) for subjects receiving staged-bilateral TKR surgery $(P=0.001)$. In addition, the mean expenses of factor supplement cost were USD 54,737 (range, USD 18,008-USD 126,482) and USD 93,878 (range, USD 34,250-USD 328,633) for simultaneous and staged TKRs, respectively $(P=0.044)$. In comparison with staged-bilateral TKRs, simultaneous procedures exhibited significantly reduced mean total admission cost by a difference of USD 40336 (USD 101,923 versus USD 61,587, $P=0.023$ ) (Fig. 3).

\section{Discussion}

The incidence of TKR performed on patients with hemophilic arthropathy is much lower than that for treating other types of knee arthritis due to its low prevalence in the general population. General orthopedic surgeons need to gather their prior treatment experiences from the results of large populationbased studies. To the best of our knowledge, previous reports related to TKR surgery for end-stage hemophilia arthropathy are limited to single-institute experiences $[6,11-19]$. This study elucidated the current status of TKR surgeries performed on patients with hemophilia by using the Taiwanese nationwide population data. Seventy-five subjects out of 996 hemophilia patients (7.5\%) received the TKR surgery within the 14 studied years in Taiwan. For patients with advanced hemophiliac arthropathy requiring TKR treatment, we concluded that the current surgery rate was lower than expected. It is well 
known that TKR surgeries operated on hemophilic patients demand more complicated techniques in association with higher rates of complications as compared with that for the general population. The underlying risks arising from factors such as bleeding, deep infection, and early prosthetic failures gives rise to more difficult issues for both orthopedic surgeons and patients.

In this study, we reported a revision- or removal-free, 10 -year prosthesis survival rate of $88.6 \%$ in Taiwan. This result is comparable to the results of previous studies $[7,11]$ on hemophilia patients receiving TKR surgeries, but it showed lower than the rates of $90-97 \%$ obtained from 10 to 15 years of follow-up among the general population receiving TKR. To achieve better prognosis, including lower incidences of complications, better physical function, and improved pain relief, enhanced surgical techniques and multidisciplinary management are recommended.

In addition to improved postoperative pain relief and knee function, it was reported that TKR surgery exhibits advantage to decrease bleeding for hemophiliac patients with end-stage arthropathy. Bae et al. [18] reported that the median preoperative consumption of coagulation factor was 4,837 units/month, which significantly decreased to 1,500 units/month at the end of first year after TKR surgery. In this study, however, no significant difference in the amount of factor consumption was noted among hemophilia patients between the period before and after TKR. However, further analysis on hemophilia subtypes revealed that patients with hemophilia $B$ received much lesser factor supplement 18 months after TKR than patients with hemophilia $\mathrm{A}(178.4 \mathrm{U} /$ day versus $413.5 \mathrm{U} /$ day; Table 3 ).

In the general population, simultaneous-bilateral TKR surgeries exhibited advantage in cost reduction accompanied with an equivalent rate of complications with that of staged-bilateral TKR surgeries [2022]. However, in patients with severe hemophilia, bilateral involvements of knee arthropathy are frequent, and TKR is indicated for both bilateral knees. Concerning perioperative bleeding, higher rate of complications and limited experience in hemophilic patients, most orthopedic surgeons prefer stagedbilateral TKR instead of simultaneous-bilateral TKR in hemophilic patients with bilateral severe knee arthropathy. It has been reported that, as compared with staged bilateral TKR, the simultaneous bilateral TKR showed advantages in less consumption of factors as a consequence of significantly reduced cost of hospitalization in hemophilia patients with bilateral severe knee arthropathy [23, 24]. In our nationwide study, 28 patients underwent bilateral TKRs, including 12 simultaneous-bilateral TKRs and 16 stagedbilateral TKRs. In agreement with results reported by Thes et al, patients receiving simultaneous-bilateral TKR surgeries showed significant reduction in their cumulative hospital stay, factor consumption, and total cost, whereas the prosthesis failure rate and PRBC transfusion amount were comparable with those of staged-bilateral TKR surgeries (Table 2). The expensive cost of coagulation factor consumption in hemophilia patients has been always a major concern in the management of hemophilia patients with arthroplasty. Analysis on cost-effectiveness revealed that the expense of factors supplement accounted for $>88.9 \%$ of the costs accrued in our study. Further study indicates that, in comparison with stagedbilateral TKRs, simultaneously bilateral TKRs saved exceeded up to 40,345 USD in the mean admission cost (USD 101,932 versus USD 61,587) in hemophilic patients receiving bilateral TKR. 


\section{Conclusion}

Based on our nation-wide study, we found the prevalence of TKA for hemophilia patients in Taiwan was around $7.5 \%$ with mean age at surgery was 32.3 years. The mean hospital stays was 15 days, the cost of factor supplement was mean USD 43,543 and admission cost is 48,326 USD. The mean daily factors usage was decreased from 235.7 unites preoperatively to 202.1 units postoperatively. The failure rate is $8.5 \%$ at mean 32.8 months (range: $2.3-95$ ) and the 10-year prosthesis survivorship was $88.6 \%$. In addition, in comparison with the staged-bilateral TKRs, the simultaneous procedures significantly reduced the mean total cost from USD 101,923 to USD $61,587(P=0.023)$. Therefore, simultaneously bilateral TKR is a safe and cost-effective procedure in hemophilic patients with bilateral severe knee arthropathy. However, this procedure should be performed by the experienced orthopedic surgeon with a special team which is also experienced in the comprehensive care of hemophilic patients.

\section{Abbreviations}

TKR: Total knee replacement; ROM: Range of motion; NHI: National health insurance; NHIRD: National health insurance research database; RCIPD: Registry for catastrophic illness patient database

\section{Declarations}

\section{Ethics approval and consent to participate}

This study was approved by our hospital's Institutional Review Board (IRB-TPE VGH No 2018-11-001AC). Informed consent is waivered due to delinked data from the data base provider.

\section{Consent for publication}

Not applicable.

\section{Availability of data and material}

The datasets generated and analyzed during the current study are available

from the corresponding author on reasonable request

\section{Competing interests}

The authors declare no competing interests.

\section{Funding}

No funding was received for this study.

\section{Authors' contributions}


CF Chen designed current study, performed research and wrote the paper; YB Yu, JP Gau and JW Chiu analyzed the data, $\mathrm{HC}$ Hsu analyzed the results and edited the manuscript.

\section{Acknowledgements}

Not applicable.

\section{References}

1. Rodriguez-Merchan EC. Musculoskeletal complications of hemophilia. HSS J. 2010;6:37-42.

2. Vanderhave KL, Caird MS, Hake M, et al. Musculoskeletal care of the hemophiliac patient. J Am Acad Orthop Surg. 2012;20:553-63.

3. Kelley SS, Lachiewicz PF, Gilbert MS, Bolander ME, Jankiewicz JJ. Hip arthroplasty in hemophilic arthropathy. J Bone Joint Surg Am. 1995;77:828-34.

4. Post M, Telfer MC. Surgery in hemophilic patients. J Bone Joint Surg Am. 1975;57:1136-45.

5. Marmor L. Total knee replacement in hemophilia. Clin Orthop Relat Res. 1977;125:192-5.

6. Zing PO, Fucentese SF, Lutz W, Brand B, Mamisch N, Koch PP. Haemophilic knee arthropathy: longterm outcome after total knee replacement. Knee Surg Sports Traumatol Arthrosc. 2012;20:2465-70.

7. Westberg M, Paus AC, Holme PA, Tjonnfjord GE. Haemophilic arthropathy: long-term outcomes in 107 primary total knee arthroplasties. Knee. 2014;21: 147-50.

8. Fehily $\mathrm{M}$, Fleming $\mathrm{P}, \mathrm{O}$ 'Shea $\mathrm{E}$, Smith $\mathrm{O}$, Smyth $\mathrm{H}$. Total knee arthroplasty in patients with severe haemophilia. Int Orthop. 2002;26:89-91.

9. Innocenti M, Civinini R, Carulli C, Villano M, Linari S, Morfini M. Amodular total knee arthroplasty in haemophilic arthropathy. Knee. 2007;14:264-8

10. Solimeno LP, Mancuso ME, Pasta G, Santagostino E, Perfetto S, Mannucci PM. Factors infuencing the long-term outcome of primary total knee replacement in haemophiliacs: a review of 116 procedures at a single institution. Br J Haematol. 2009;145:227-34.

11. Panotopoulos J, Ay C, Trieb K, Schuh R, Windhager R, Wanivenhaus HA. Outcome of total knee arthroplasty in hemophilic arthropathy. J Arthroplasty. 2014;29:749-52.

12. 12. Jenkins PJ, Ekrol I, Lawson GM. Total knee replacement in patients with haemophilia: the Scottish experience. Scott Med J. 2013;58:223-7.

13. 13. Wang K, Street A, Dowrick A, Liew S. Clinical outcomes and patient satisfaction following total joint replacement in haemophilia--23-year experience in knees, hips and elbows. Haemophilia. 2012;18:86-93.

14. 14. Uprichard J, Adamidou D, Goddard NJ, Mann HA, Yee TT. Factor IX replacement to cover total knee replacement surgery in haemophilia B: a single-centre experience, 2000-2010. Haemophilia. 2012;18:46-9. 
15. 15. Goddard NJ, Mann HA, Lee CA. Total knee replacement in patients with end-stage haemophilic arthropathy: 25-year results. J Bone Joint Surg Br. 2010; 92:1085-9.

16. 16. Chiang CC, Chen $P Q$, Shen MC, Tsai W. Total knee arthroplasty for severe haemophilic arthropathy: long-term experience in Taiwan. Haemophilia. 2008;14:828-34.

17. 17. Rodriguez-Merchan EC. Total knee replacement in haemophilic arthropathy. J Bone Joint Surg Br. 2007;89:186-8.

18. 18. Bae DK, Yoon KH, Kim HS, Song SJ. Total knee arthroplasty in hemophilic arthropathy of the knee. J Arthroplasty. 2005;20:664-8.

19. 19. Sheth DS, Oldfield D, Ambrose C, Clyburn T. Total knee arthroplasty in hemophilic arthropathy. J Arthroplasty. 2004;19:56-60.

20. 20. Lin AC, Chao E, Yang CM, Wen HC, Ma HL, Lu TC. Costs of staged versus simultaneous bilateral total knee arthroplasty: a population-based study of the Taiwanese National Health Insurance Database. J Orthop Surg Res. 2014;9:59-67.

21. 21. Odum SM, Troyer JL, Kelly MP, Dedini RD, Bozic KJ. A cost-utility analysis comparing the costeffectiveness of simultaneous and staged bilateral total knee arthroplasty. J Bone Joint Surg Am. 2013;95:1441-9.

22. 22. Reuben JD, Meyers SJ, Cox DD, Elliott M, Watson M, Shim SD. Cost comparison between bilateral simultaneous, staged, and unilateral total joint arthroplasty. J Arthroplasty.1998;13:172-9.

23. 23. Thes A, Molina V, Lambert T. Simultaneous bilateral total knee arthroplasty in severe hemophilia: a retrospective cost-effectiveness analysis. Orthop Traumatol Surg Res. 2015;101:147-50.

24. Mortazavi SM, Haghpanah B, Ebrahiminasab MM, Baghdadi T, Hantooshzadeh R, Toogeh G. Simultaneous bilateral total knee arthroplasty in patients with haemophilia: a safe and cost-effective procedure? Hemophilia. 2016;22,303-7.

\section{Figures}




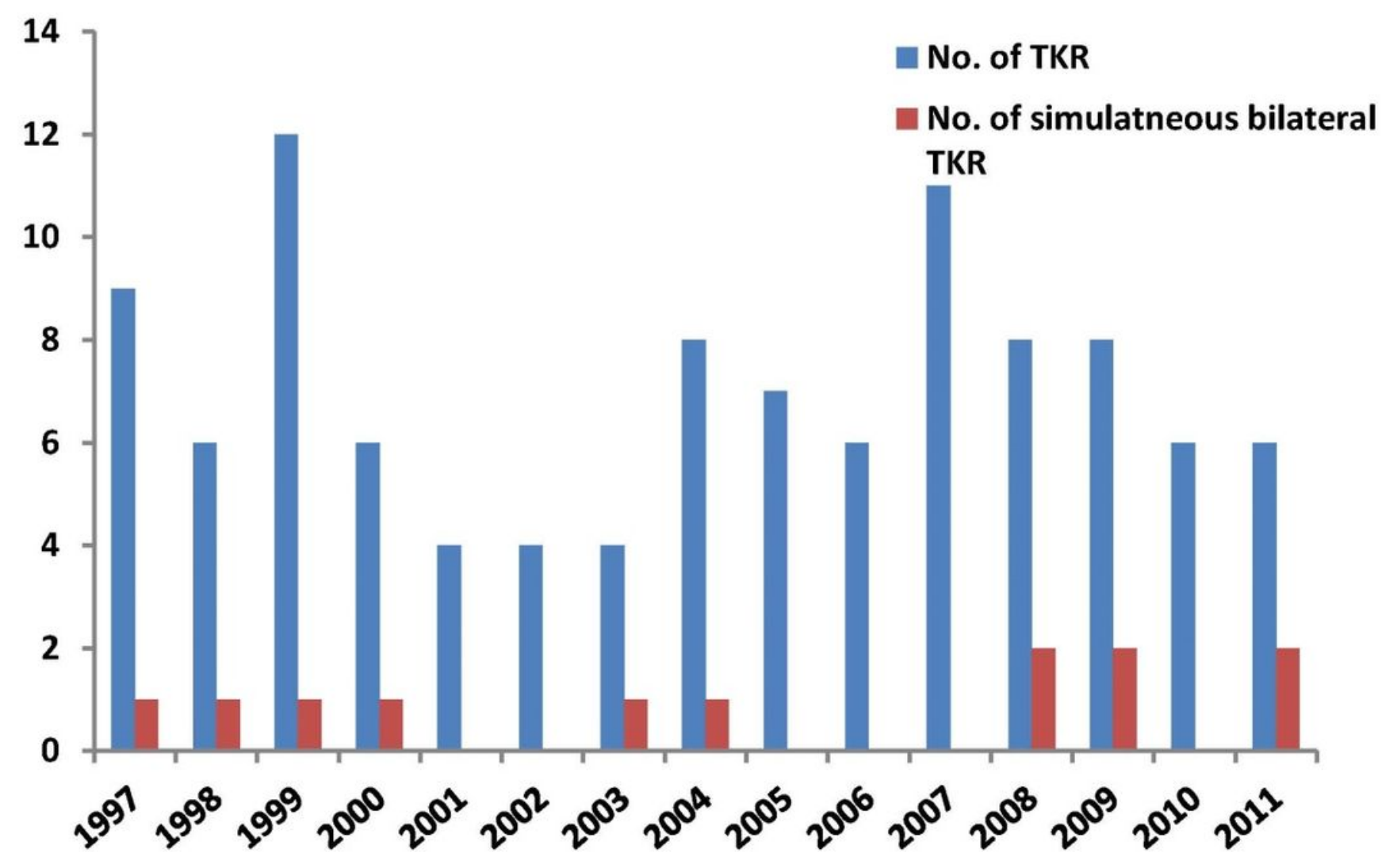

Figure 1

The distribution of TKR numbers for Taiwan hemophilia patients between 1997 and 2011. 


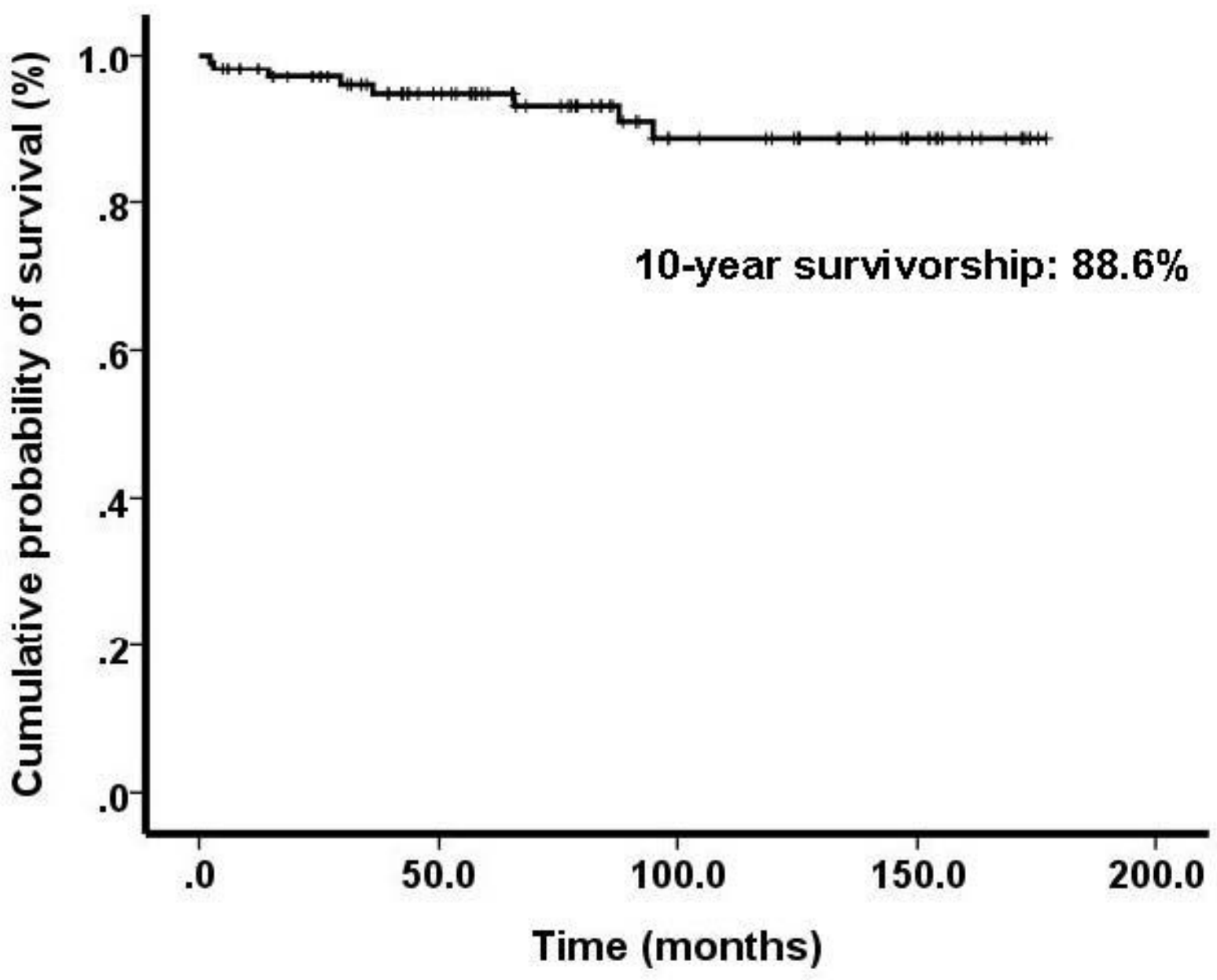

Figure 2

The Kaplan-Meier survivorship curve depicting the 10 -year survival rate of $88.6 \%$. 
A

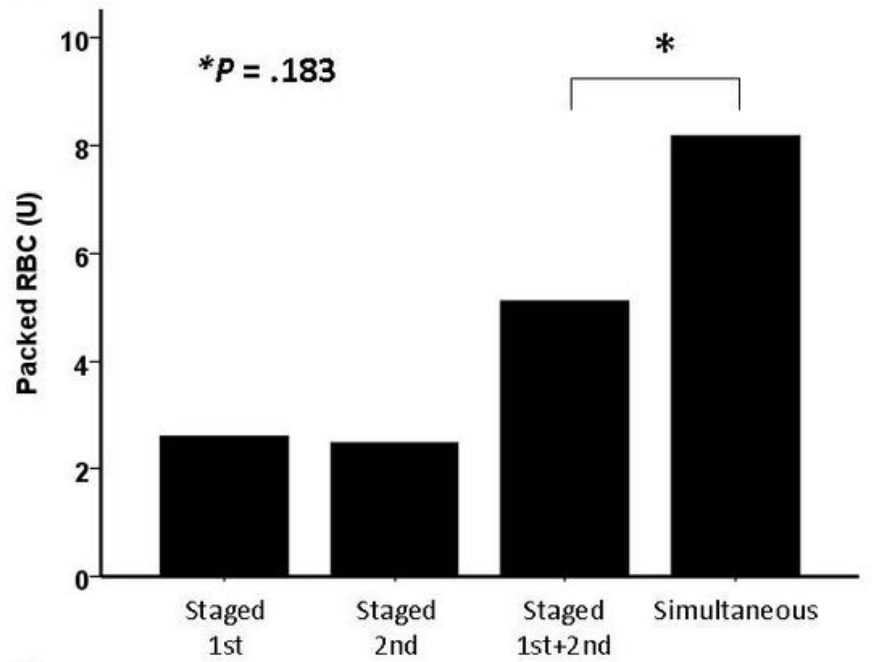

C

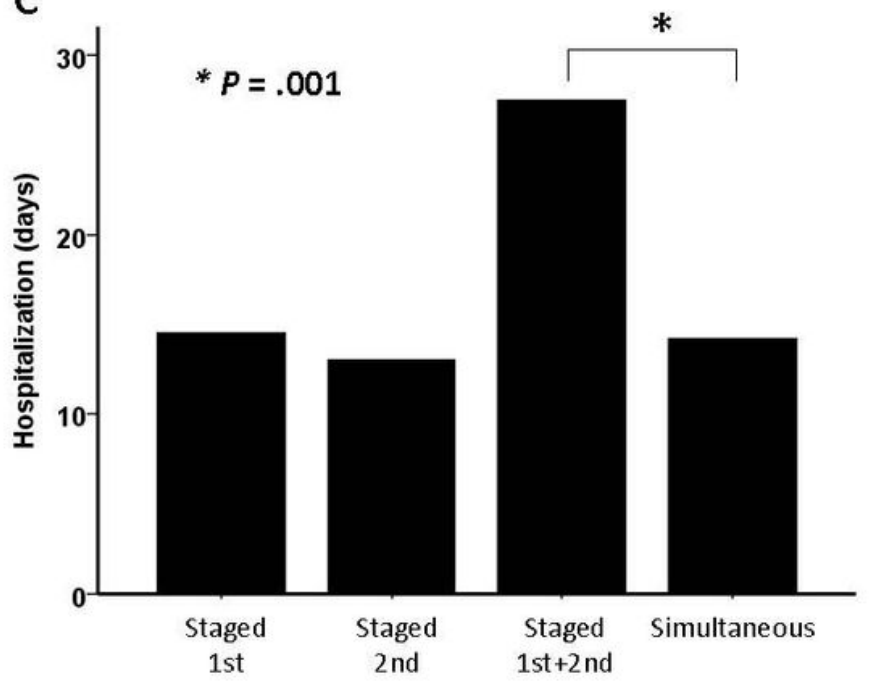

B

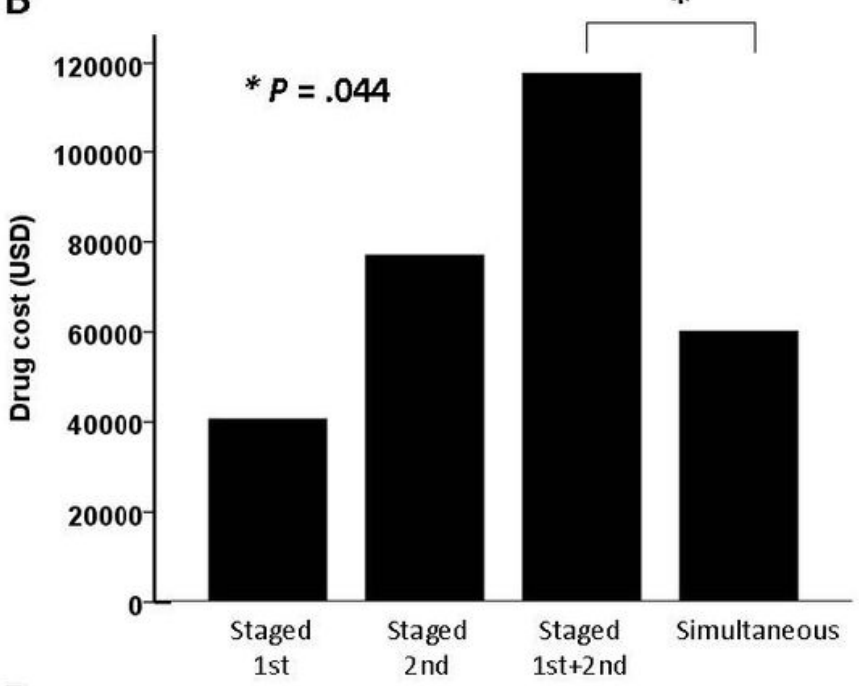

D

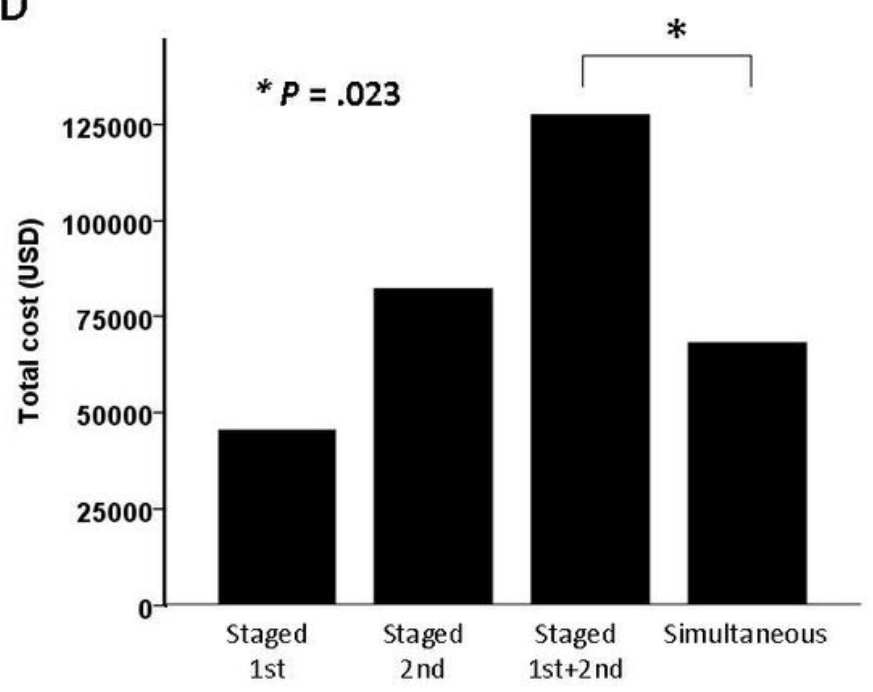

Figure 3

Comparison of staged bilateral TKR for hemophilia patients with, the simultaneous group showing that the latter had significantly lower drug cost (B), shorter hospitalization stay (C), lower total cost (D), and more blood transfusion unit (A). 